\title{
Designing a Cost-Time-Quality-Efficient Grinding Process Using MODM Methods
}

\author{
Meysam Mahjoob and Pouneh Abbasian
}

\begin{abstract}
In this paper, a multi-objective mathematical model is developed to optimize the grinding parameters Such as grinding time, cost, and related surface quality metrics such as workpiece speed, depth of cut and wheel speed. The mathematical model consists of three conflicting objective functions subject to wheel wear and production rate constraints. Exact methods cannot solve the NLP model in few seconds, therefore using Meta-heuristic algorithms that provide near-optimal solutions is not suitable. Considering this, five multi-objective decision-making (MODM) have been used to solve the multi-objective mathematical model using general algebraic modelling system (GAMS) software to achieve the optimal parameters of the grinding process. The MODM methods provide different effective solutions where the decision-maker (DM) can choose each solution in different situations. Different criteria have been considered to evaluate the performance of the five MODM methods. Also, a technique for order of preference by similarity to ideal solution (TOPSIS) has been used to obtain the priority of each method and determine which MODM method performs better considering all criteria simultaneously. The results indicated that the weighted sum method (WSM) and goal programming method (GP) are the best MODM methods, as both of them provide competitive solutions. In addition, these methods obtained solutions that have minimum grinding time, cost, and surface roughness among other MODM methods.
\end{abstract}

Keywords - Goal programming; Grinding; Multi-objective decision making; TOPSIS.

\section{INTRODUCTION}

During the past decade, many researchers have focused on optimizing the grinding process. Production costs, machining time, and surface quality of machined products can be improved by achieving optimal grinding process parameters [1]

Baskar et al. [2] proposed an ant colony-based optimization approach to optimize the grinding parameters using a multi-objective model with a weighted method under thermal damage, wheel wear parameter, surface finish, and tool stiffness constraints. They compared the results with Quadratic programming (QP) and Genetic Algorithm (GA) presented in previous researches. They showed that the ant colony-based optimization method performs better in solving the grinding process optimization problem. Saravanan et al. [3] proposed a new GA to solve the weighted objective function of the grinding optimization problem. The results declared that their approach is a robust and easy method compared to the previous studies. More researches in the

\footnotetext{
Submitted on January 21, 2022.

Published on March 04, 2022.

Meysam Mahjoob, Department of Industrial and Systems Engineering, Fouman Faculty of Engineering, College of Engineering, University of Tehran, Fouman, Iran.

(e-mail: mahjoob_m@ut.ac.ir)
}

optimization of the grinding process include [4]-[19]. Diverse optimization methods are suggested considering the effect of the grinding parameters such as wheel speed, workpiece speed, depth of dressing, lead of dressing on the manufactured products. Gholami and Azizi [20] presented a non-dominated sorting genetic algorithm (NSGA II) to obtain the optimal values of workpiece speed, wheel speed, and depth of cut in the grinding process. They presented different Pareto solutions for the multi-objective optimization problem selected by the decision-maker (DM) under different scenarios. Multi-choice goal programming (MCGP) is another concept that provides a range of ideal solutions for each objective function [21], thereby it is more flexible than goal programming (GP) in situations when DM underestimates the initial ideal solution set for the model. lack of available recourses and information could be reasons for changes in DM's preferences in different situations and times. Using multiple utility functions defined for each objective function, [22], [23] were able to solve multiobjective decision making problems using the Bayesian theory.

The majority of previous studies combined the objective functions to construct a single weighted objective function in order to optimize the grinding parameters. This conversion may lead to significant deviations in obtaining the optimal value of the decision variables and the solution's quality. Also, the solutions' quality strongly depends on the weight assigned to each objective function, where finding suitable weights for each objective function is another complex decision. Moreover, exact methods can solve the NLP model of the grinding process in a few seconds. Therefore, using Meta-heuristic algorithms that provide near-optimal solutions is not suitable. There are many other solution methods that handle multi-objective optimization problems, such as multi-objective decision making (MODM) methods [22].

As we mentioned earlier, in the case of not-so-complex problems, the exact methods would solve problems in a few seconds. Therefore, five MODM methods have been used to solve the multi-objective mathematical model of the problem using the general algebraic modeling system (GAMS) software which provides exact solutions for optimization problems. The solution obtained by each method is an effective solution to the optimization problem and the DM can choose each MODM method in different situations. In addition, MODM methods can provide better solutions than

Pouneh Abbasian, Department of Multidisciplinary Engineering, College of Engineering, Texas A\&M University, USA

(e-mail: p.abbasian@tamu.edu) 
meta-heuristic algorithms such as NSGA-II, MOPSO and etc. At the end we compared the performance of the MODM methods using different criteria including objective functions value and CPU-Time. Technique for order of Preference by Similarity to Ideal Solution (TOPSIS) method has been used to determine the best MODM method in solving the multiobjective mathematical model of the grinding process.

\section{MATHEMATICAL MODEL}

We used the multi-objective mathematical model of the grinding parameters proposed by [20]. The mathematical model of the problem includes three objective functions, a non-linear constraint and upper and lower bounds for the decision variables. In this research, the following notation has been used:

$M_{c}:$ Cost per hour of labor and administration $(\$ / h)$

p: Number of workpieces loaded on the table

$L_{w}$ : Length of workpiece $(\mathrm{mm})$

$L_{e}$ : Empty length of grinding $(\mathrm{mm})$

$b_{w}$ : Width of workpiece $(\mathrm{mm})$

$b_{e}$ : Empty width of grinding $(\mathrm{mm})$

$f_{b}$ : Cross feed rate ( $\mathrm{mm} /$ pass)

$a_{w}$ : Total thickness of cut $(\mathrm{mm})$

$a_{p}$ : Down feed of grinding $(\mathrm{mm} /$ pass $)$

$S_{p}:$ Number of sparks out grinding (pass)

$d_{e}$ : Diameter of wheel $(\mathrm{mm})$

$b_{s}$ : Width of wheel $(\mathrm{mm})$

$G$ : Grinding ratio

$S_{d}$ : Distance of wheel idling $(\mathrm{mm})$

$V_{r}$ : Speed of wheel idling $(\mathrm{mm} / \mathrm{min})$

$t_{i}$ : Time of loading and unloading workpiece (min)

$t_{c h}$ : Time of adjusting machine tool ( $\mathrm{min}$ )

$N_{d}$ : Total number of pieces to be grouped during the life of dressing

$N_{t}$ : Batch size of workpiece

$N_{t d}$ : Total number of workpieces to be grouped during the life of dressing

$C_{d}:$ Cost of dressing (\$)

$C_{s}$ : Cost of wheel per $\mathrm{mm}^{3}\left(\$ / \mathrm{mm}^{3}\right)$

$C_{T}:$ Production cost $(\$)$

$R_{a}$ : Surface roughness $(\mu \mathrm{m})$

Doc: Depth of dressing $(\mathrm{mm})$

L: Lead of dressing $(\mathrm{mm} / \mathrm{rev})$

WRP: Workpiece removal parameters $\left(\mathrm{mm}^{3} / \mathrm{min} N\right)$

$W W P$ : Wheel wear parameter $(\mathrm{mm} 3 / \min N)$

$T$ : Total grinding time

$N_{p}:$ Number of passes

$t_{m}$ : Time of machining (min)

$t_{a}$ : Time of workpiece approach (min)

$V_{s}:$ Wheel speed $(\mathrm{m} / \mathrm{min})$

$t_{e}:$ Extra workpiece path time (min)

$V_{w}:$ Work piece speed $(\mathrm{m} / \mathrm{min})$

As in [20], the mathematical model of the problem can be represented as:

$$
\operatorname{Min} R_{a}=4.456 V_{w}^{0.229} \cdot a_{w}^{-1.649} \cdot V_{s}^{-0.964}
$$

$\operatorname{MinT}=\frac{N_{p} \times L_{w}}{V_{w}}+t_{c h}+t_{i}+\frac{L_{e}}{V_{w}}+\frac{L_{e}}{V_{w}}$

$\operatorname{Min} C_{T}=\frac{M_{c}}{60 p}\left(\frac{L_{w}+L_{e}}{1000 V_{w}}\right)\left(\frac{b_{w}+b_{e}}{f_{b}}\right)\left(\frac{a_{w}}{a_{p}}+S_{p}+\frac{a_{w} b_{w} L_{w}}{\pi D_{e} b_{s} a_{p} G}\right)+$ $\frac{M_{c}}{60 p}\left(\frac{S_{d}}{V_{r}}+t_{1}\right)+\frac{M_{c}}{60} \frac{t_{c h}}{N_{t}}+\frac{M_{c}}{60 p} \frac{1}{N_{d}} \frac{\pi D_{e} b_{S}}{1000 L V_{s}}+C_{s}\left(\frac{a_{w} b_{w} L_{w}}{p G}+\right.$ $\left.\frac{\pi D o c b_{s} D_{e}}{p N_{d}}\right)+\left(\frac{C_{d}}{p N_{t d}}\right)$

Subject to:

$$
\begin{aligned}
& W R P=94.4 \frac{\left(\frac{2 D o c}{3 L}+1\right) L^{\frac{11}{19}}\left(\frac{V_{w}}{V_{S}}\right)^{\frac{3}{19}} V_{S}}{D_{e}^{\frac{43}{304}} V O L^{0.47} d_{g}^{\frac{5}{38}} R_{c}^{\frac{27}{19}}} \\
& W W P=\frac{K_{a} a_{p} d_{g}^{\frac{5}{38}} R_{c}^{\frac{27}{19}}}{D_{e}^{\left(\frac{1.2}{V O L}-\frac{43}{304}\right)} V O L^{0.38}} \frac{\left(1+\frac{D o c}{L}\right) L^{\frac{27}{19}}\left(\frac{V_{S}}{V_{w}}\right)^{\frac{3}{19}} V_{w}}{\left(1+\frac{2 D o c}{3 L}\right)} \\
& G \leq \frac{W R P}{W W P} \\
& 1000 \leq V_{s} \leq 3000 \\
& 10 \leq V_{w} \leq 50 \\
& 0.04 \leq a_{w} \leq 0.12
\end{aligned}
$$

The aims of (1)-(3) are to minimize the production costs, grinding time and surface roughness simultaneously. Inequality (6) determines the wheel wear constraint and (7)(9) indicates the upper and lower bounds of each decision variables.

\section{SOLUTION METHODS}

The mathematical model developed in the previous section is a constraint bi-objective mixed integer linear programming (MILP) model. The optimal solution of the developed biobjective model is an ideal solution that minimizes both objective functions simultaneously. Since the objective functions are in conflict and so there is no such optimal solution, thus we need to make a compromise solution between the objectives [24]-[26]. In these cases, the multiobjective solution methods should be utilized to solve the model. In this paper five MODM methods presented by [27] utilized to solve the multi objective optimization model of the grinding process. As in [28]-[30], five MODM methods are defined as follows:

\section{A. Individual Optimization Method}

This method considers each objective function separately, solves the optimization problem and obtains the optimal solution. This method is based on this concept that the optimal solution of each objective function is an effective solution for the multi-objective optimization problem.

\section{B. Lp-Metric Method}

This method is based on the concept of minimizing the digression between objective functions and their ideal solution obtained by the individual optimization method. 
Equation (10) describes the Lp-Metric method. Minimization type objective functions must be converted to maximization type.

$$
\operatorname{Min} D=\left(\sum_{i=1}^{n}\left(\frac{f_{i}^{*}-f_{i}}{f_{i}^{*}}\right)^{r}\right)^{\frac{1}{r}}
$$

\section{Weighted Sum Method (WSM)}

In WSM method, a positive weight is assigned to each objective function. The assigned weights to objective functions must satisfy the $\sum_{i=1}^{n} w_{i} f_{i}=1$ constraint. The goal is to minimize the combined objective function which is weighted sum of the objective functions as following:

$$
\operatorname{Max} U\left(f_{1}, f_{2}, \ldots, f_{n}\right)=\sum_{i=1}^{n} w_{i} f_{i}
$$

\section{Max-Min Method}

The purpose of Max-Min method is to maximize the minimum values of objective functions divided to their ideal solutions. Equation (12) indicates the mathematical model of the method.

$$
\operatorname{Max}\left(\operatorname{Min}\left(\frac{f_{1}}{f_{1}^{*}}, \frac{f_{2}}{f_{2}^{*}}, \ldots, \frac{f_{n}}{f_{n}^{*}}\right)\right)
$$

\section{E. Goal Attainment Method}

The Goal attainment method aims to find solutions for each objective function which minimizes a weighted deviation of objective function values with their related ideal solution. The assigned weights to deviations in objective functions must satisfy the $\sum_{i} w_{i}=1$ constraint. The mathematical model of the problem is as follows:

$$
\begin{aligned}
& \text { Min } Z \\
& \text { s.t.: } \\
& f_{i}+w_{i} Z \geq f_{i}^{*} ; \forall i
\end{aligned}
$$

\section{F. Goal Programming Method (GP)}

In GP method the aim is to find a solution which minimizes the positive or negative deviations between objective functions and their relevant ideal solutions. Equation (14) defines the mathematical model of the Goal Programming method.

$$
\begin{aligned}
& \text { Min } \sum_{i=1}^{n} a_{i} g_{i}\left(d_{i}^{+}, d_{i}^{-}\right) \\
& \text {s.t. } \\
& f_{i}-d_{i}^{+}+d_{i}^{-}=f_{i}^{*} ; \forall i \\
& d_{i}^{+} \geq 0, d_{i}^{-} \geq 0 ; \forall i
\end{aligned}
$$

\section{EXPERIMENTAL EXAMPLE}

Gholami and Azizi [20] used nine billets of 1.2080 steel with $30 \times 20 \times 10 \mathrm{~mm}$ dimensions to perform the grinding process. The material of the abrasive grinding wheel has been selected from aluminum oxide. In order to dress the grinding wheel a single point diamond dresser has been utilized. To optimize the grinding process the values of the input parameters have been selected as [20] in Table I.

Five MODM methods presented above to optimize the grinding parameters have been applied to achieve the best finish surface, minimum grinding cost and time using GAMS software. For this purpose, a computer with i7 CPU and 8GB of ram has been utilized. Different criteria have been considered to evaluate the performance of the five MODM methods such as objective function values and CPU-Time [31].

\section{A. Objective Functions Value}

The three objective functions value have been considered as three different criteria to compare the MODM methods in term of ability to achieve the best optimal solution [32], [33].

\section{B. CPU-Time}

CPU-Time criterion is another important factor to compare the MODM methods in term of time needed to solve the multi-objective optimization problem [34]-[36].

The result of solving the optimization problem using five MODM methods is presented in Table II.

TABLE II: RESULTS OF MODM METHODS

\begin{tabular}{cccccccc}
\hline Method & $V_{w}$ & $V_{s}$ & $a_{w}$ & $R_{a}$ & $\mathrm{~T}$ & $C_{T}$ & $\begin{array}{c}\text { CPU- } \\
\text { Time }\end{array}$ \\
\hline $\begin{array}{c}\text { Individual } \\
\text { optimization } \\
\text { method }\end{array}$ & --- & -- & -- & 0.111 & 25 & 5.336 & -- \\
$\begin{array}{c}\text { Lp-Metric } \\
\text { Max-Min }\end{array}$ & 31.60 & 3000 & 0.12 & 0.144 & 26.7 & 5.656 & 0.100 \\
$\quad 10$ & 1000 & 0.109 & 0.375 & 37 & 7.149 & 0.270 \\
$\begin{array}{c}\text { Goal } \\
\text { attainment }\end{array}$ & 10 & 1000 & 0.047 & 1.508 & 37 & 6.733 & 0.110 \\
$\begin{array}{c}\text { WSM } \\
\text { Goal }\end{array}$ & 50 & 3000 & 0.12 & 0.16 & 25 & 5.445 & 0.094 \\
programming & 50 & 3000 & 0.12 & 0.16 & 25 & 5.445 & 0.098 \\
\hline
\end{tabular}

As in Table II, each solution obtained by each MODM method is an effective solution for the optimization problem. Each solution can be preferred by the DM in different situations. For example, when the importance of the surface quality is higher for the decision maker, he/she will choose the Lp-Metric method which obtains a solution with the minimum $R_{a}$ comparing to other methods. Fig. 1, 2 and 3 show the objective function values obtained by each MODM method. Fig. 4 depicts the CPU-Time of the MODM methods.

TABLE I: VALUES OF THE PARAMETERS

\begin{tabular}{cccccccccccc}
\hline$M_{c}$ & $\mathrm{p}$ & $L_{e}$ & $L_{w}$ & $b_{w}$ & $b_{e}$ & $f_{b}$ & $\mathrm{G}$ & $N_{t d}$ & $d_{e}$ & $V_{w \min }$ & $V_{w \max }$ \\
\hline 30 & 1 & 15 & 30 & 20 & 10 & 2 & 60 & 2000 & 500 & 10 & 50 \\
\hline$C_{T}^{*}$ & $R_{c}$ & $t_{e}$ & $V_{r}$ & $t_{i}$ & $t_{c h}$ & $N_{d}$ & $N_{t}$ & $N_{p}$ & $C_{d}$ & $a_{w \min }$ & $a_{w \max }$ \\
\hline 3 & 58 & 0.02 & 25 & 2 & 20 & 4 & 4 & 4 & 75 & 0.04 & 0.12 \\
\hline$t_{a}$ & $s_{p}$ & $b_{s}$ & $\mathrm{Doc}$ & $\mathrm{L}$ & $K_{a}$ & $\mathrm{vol}$ & $d_{g}$ & $S_{d}$ & $C_{s}$ & $V_{s \min }$ & $V_{s \max }$ \\
\hline 0.02 & 3 & 50 & 0.02 & 0.02 & 0.0869 & 6.99 & 0.3 & 10 & 0.003 & 1000 & 3000 \\
\hline
\end{tabular}




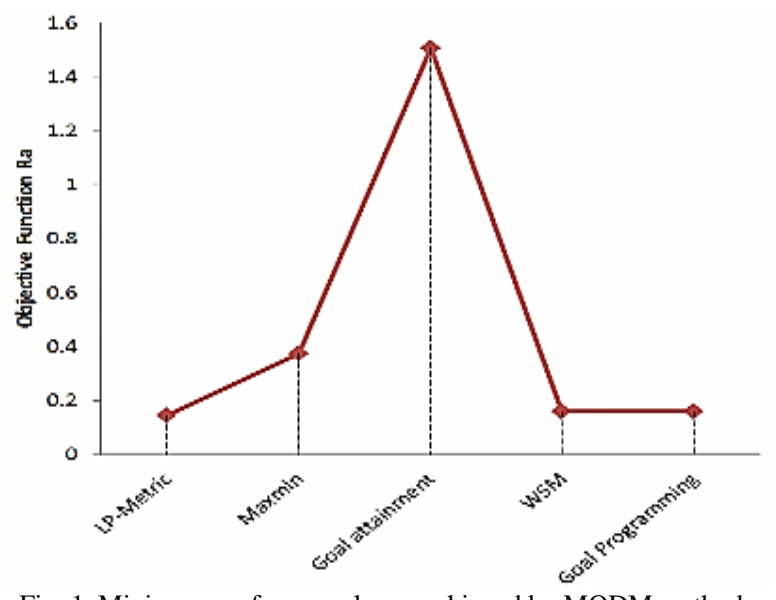

Fig. 1. Minimum surface roughness achieved by MODM methods.

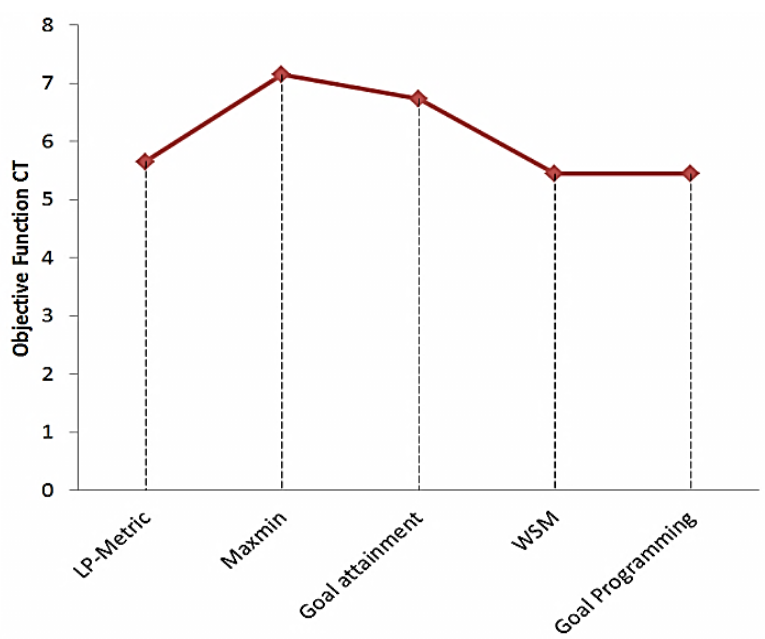

Fig. 2. Minimum production cost obtained using each MODM method.

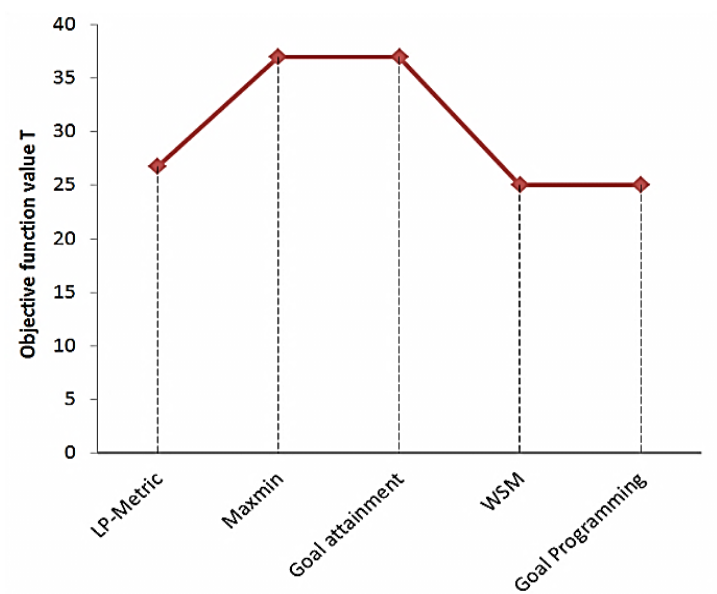

Fig. 3. Minimum total grinding time gained by MODM methods.

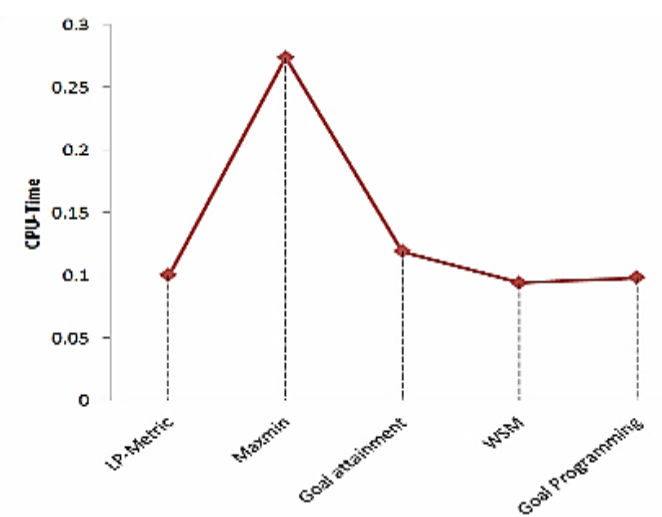

Fig. 4. CPU-Time of each MODM method.

\section{COMPARING MODM MethodS UsING TOPSIS Method}

In order to compare MODM methods, first we must build the decision matrix as presented in Table III.

\begin{tabular}{ccccc}
\multicolumn{5}{c}{ TABLE III: DECISION MATRIX } \\
$\begin{array}{ccccc}\text { Criteria } \\
\text { Method }\end{array}$ & $R_{a}$ & $\mathrm{~T}$ & $C_{T}$ & $\begin{array}{c}\text { CPU- } \\
\text { Time }\end{array}$ \\
\hline Lp-Metric & 0.144 & 26.7 & 5.656 & 0.100 \\
Max-Min & 0.375 & 37 & 7.149 & 0.270 \\
Goal attainment & 1.508 & 37 & 6.733 & 0.110 \\
WSM & 0.16 & 25 & 5.445 & 0.094 \\
Goal programming & 0.16 & 25 & 5.445 & 0.098 \\
\hline
\end{tabular}

\section{A. TOPSIS Method}

TOPSIS method proposed by [37]. The concept of TOPSIS method is based on selection of an alternative which has longest (shortest) distance from the negative (positive) ideal solution. TOPSIS method has been applied to determine the best MODM method in solving the multiobjective optimization problem. As objective function values are more important to us than CPU-Time, we allocated the $80 \%$ weight for objective functions criteria and $20 \%$ weight for CPU-Time criterion. The weight of each criterion is given in Table IV.

TABLE IV: WEIGHTS OF THE CRITERIA

\begin{tabular}{ccccc}
\multicolumn{5}{c}{ TABLE IV: WEIGHTS OF THE CRITERIA } \\
\hline Criteria & $R_{a}$ & $\mathrm{~T}$ & $C_{T}$ & CPU-Time \\
\hline Weight $_{j}$ & 0.266 & 0.266 & 0.266 & 0.20 \\
\hline
\end{tabular}

First, we need to normalize the decision matrix using Euclidean Norm:

$$
n_{i j}=\frac{r_{i j}}{\sqrt{\sum_{i} r_{i j}^{2}}}
$$

Where $r$ is the decision matrix values and $n$ is normalized decision matrix using Euclidean Norm. $i$ is our chosen MODM method and $j$ is the criterion index. To obtain a

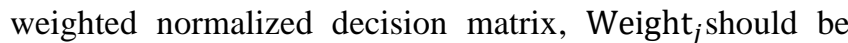
multiplied by a normalized decision matrix, as shown in (16).

weighted normalized matrix $=\left[v_{i j}\right]_{m \times n}, \quad v_{i j}=$ Weight $_{j} \times n_{i j}$

where, Weight ${ }_{j}$ is the weight of each of the MODM methods. Therefore, we can determine the ideal positive solution and the ideal negative solution as follows:

idealsolution $^{+}=\left\{\max _{i} v_{i j}: j \in\right.$

$\left.j^{+}, \min _{i} v_{i j}: j \in j^{-}\right\}$

idealsolution $^{-}=\left\{\max _{i} v_{i j}: j \in\right.$

$\left.j^{-}, \min _{i} v_{i j}: j \in j^{+}\right\}$

Distance from the positive and negative ideal solutions for each MODM method have been calculated using below formulas: 


$$
\begin{aligned}
& d_{i}^{+}=\sqrt{\sum_{j=1}^{n}\left(v_{i j}-\text { idealsolution }^{+}\right)} \\
& d_{i}^{-}=\sqrt{\sum_{j=1}^{n}\left(v_{i j}-\text { idealsolution }^{-}\right)}
\end{aligned}
$$

Equation (21) presents the Similarity ratio formula.

$$
S_{i}^{+}=\frac{d_{i}^{-}}{d_{i}^{-}+d_{i}^{+}}
$$

The results achieved from TOPSIS method are presented in Table V.

\begin{tabular}{cccccc}
\multicolumn{6}{c}{ TABLE V: TOPSIS METHOD RESULTS } \\
\hline $\begin{array}{c}\text { Similarity } \\
\text { ratio }\end{array}$ & $\begin{array}{c}\text { Lp- } \\
\text { Metric }\end{array}$ & $\begin{array}{c}\text { Max- } \\
\text { Min }\end{array}$ & $\begin{array}{c}\text { Goal } \\
\text { attainment }\end{array}$ & WSM & $\begin{array}{c}\text { Goal } \\
\text { programming }\end{array}$ \\
\hline$S_{i}^{+}$ & 0.9677 & 0.6037 & 0.2876 & 0.9896 & 0.9861 \\
\hline
\end{tabular}

The MODM method with larger similarity ratio performs better in solving the mathematical model of the multiobjective optimization problem of the grinding process. Table VI presents five MODM methods ranked according to their similarity ratio.

\begin{tabular}{cc} 
TABLE VI: MODM METHODS RANKING \\
\hline Method & Rank \\
\hline Lp-Metric & 3 \\
Max-Min & 4 \\
Goal attainment & 5 \\
WSM & 1 \\
Goal programming & 2 \\
\hline
\end{tabular}

The results indicate that the WSM provides the best solution to the multi-objective optimization problem. Also, GP performs significantly better than other MODM methods in solving optimization problem of the grinding process.

\section{CONCLUSION}

In this paper a multi objective mathematical model have been used to optimize the grinding parameters in an experimental case study to achieve best possible grinding surface, minimum production time and cost. Combining objective functions using weighted approaches may lead to significant deviations in obtaining the optimal values of the decision variables and the quality of the solution. To avoid this, we used five different MODM methods to solve the multi objective optimization problem. Different criteria such as objective functions value and CPU-Time have been considered to compare these MODM methods. The results indicated that the solutions obtained by each MODM method is an effective solution for the multi objective model and the decision maker can choose each MODM method in different situations. TOPSIS method has been utilized to determine the best MODM method considering comparing criteria simultaneously. The results indicated that the WSM and GP methods are the best MODM methods in solving multi objective optimization problem of the grinding process.

\section{REFERENCES}

[1] Khalilpourazari S, \& Khalilpourazary S. SCWOA: an efficient hybrid algorithm for parameter optimization of multi-pass milling process Journal of Industrial and Production Engineering. 2018b;1-13.

[2] Baskar N, Saravanan R, Asokan P, Prabhaharan G. Ants colony algorithm approach for multi-objective optimisation of surface grinding operations. Int $J$ Adv Manufact Technol. 2004; 23:311317.doi:10.1007/s00170-002-1533-6.

[3] Saravanan R, Asokan P, Sachidanandam M. A multi-objective genetic algorithm (GA) approach for optimization of surface grinding operations. Int J Mach Tools and Manufact. 2002; 42:13271334.doi:10.1016/S0890-6955(02)00074-3.

[4] Malkin S, Koren Y, Ber A. Off-line grinding optimization with a micro-computer. CIRP Annals - Manufact Technol. 1980; 29:213216.doi:10.1016/S0007-8506(07)61324-9.

[5] Slowik A, Slowik J. Multi-objective optimization of surface grinding process with the use of evolutionary algorithm with remembered Pareto set. Int $J$ Adv Manufact Technol. 2008; 37:657669.doi:10.1007/s00170-007-1013-0.

[6] Krishna AG. Optimization of surface grinding operations using a differential evolution approach. J Mater Process Technol. 2007;183: 202-209. doi: 10.1016/j.jmatprotec.2006.10.010.

[7] Rabiei F, Rahimi AR, Hadad MJ, Ashrafijou M. Performance improvement of minimum quantity lubrication (MQL) technique in surface grinding by modeling and optimization. J Cleaner Prod. 2015; 86:447-460. doi: 10.1016/j.jclepro.2014.08.045.

[8] Zhang G, Liu M, Li J, Ming WY, Shao XY, Huang Y. Multi-objective optimization for surface grinding process using a hybrid particle swarm optimization algorithm. Int J Adv Manuf Technol. 2014; 71:1861-1872. doi: 10.1007/s00170-013-5571-z.

[9] Kwak JS. Application of Taguchi and response surface methodologies for geometric error in surface grinding process. Int J Mach Tools Manufact. 2005; 45:327-334. doi: 10.1016/j.ijmachtools.2004.08.007.

[10] Kahhal P, Ahmadi Brooghani SY, Deilami Azodi H. Multi-objective optimization of sheet metal forming die using Genetic Algorithm Coupled with RSM and FEA. J Failure Analy Preve. 2013; 13:771778.doi: 10.1007/s11668-013-9747-5.

[11] Kwak JS, Kim IK. Parameter optimization of surface grinding process based on Taguchi and response surface methods. Key Eng Mater. 2006; 306:709-714. doi: 10.4028/www.scientific.net/KEM.306308.709 .

[12] Yusup N, Zain AM, Hashim SZM. Evolutionary techniques in optimizing machining parameters: Review and recent applications (2007-2011). Exp Sys Appl. 2012; 39:9909-9927.doi: 10.1016/j.eswa.2012.02.109.

[13] Ben Fredj N, Amamou R. Ground surface roughness prediction based upon experimental design and neural network models. Int J Adv Manuf Technol. 2006; 31:24-36.doi:10.1007/s00170-005-0169-8.

[14] Lin X, Li H. Enhanced Pareto particle swarm approach for multiobjective optimization of surface grinding process. Proc. 2 st Int. Conf. Intel Information Technol Appl. 2008; 1:618-623.

[15] Lee KM, Hsu MR, Chou JH, Guo CY. Improved differential evolution approach for optimization of surface grinding process. Exp Sys Appl. 2011; 38:5680-5686. doi: 10.1016/j.eswa.2010.10.067.

[16] Mukherjee I, Ray PK. Optimal process design of two-stage multiple responses grinding processes using desirability functions and metaheuristic technique. Appl Soft Comput. 2008; 8:402-421.doi: 10.1016/j.asoc.2007.02.005

[17] Khalilpourazari, S, \& Khalilpourazary, S. A lexicographic weighted Tchebycheff approach for multi-constrained multi-objective optimization of the surface grinding process. Engineering Optimization. 2007; 49(5), 878-895.

[18] Khalilpourazari, S, \& Khalilpourazary, S. Optimization of production time in the multi-pass milling process via a Robust Grey Wolf Optimizer. Neural Computing and Applications. 2016; 1-16.

[19] Khalilpourazari, S, \& Khalilpourazary, S. A Robust Stochastic Fracta Search approach for optimization of the surface grinding process. Swarm and Evolutionary Computation. 2018a; 38, 173-186.

[20] Gholami MH, Azizi MR. Constrained grinding optimization for time, cost, and surface roughness using NSGA-II. Int $J$ Adv Manufact Technol. 2014; 73:981-988.doi:10.1007/s00170-014-5884-6.

[21] Chang C-T. Multi-choice goal programming. Omega 2007; 35:389396.

[22] Abbasian P, Mahdavi-Amiri N, Fazlollahtabar H. Multiple utility constrained multi-objective programs using Bayesian theory. Journal of Industrial Engineering International. 2018; 14(1):111-8.

[23] Abbasian P, Mahdavi-Amiri N, Fazllolahtabar H. Modeling and optimizing of a non-constrained multi-objective problem having 
multiple utility functions using the Bayesian theory. J Inf Sci Comput Technol. 2015; 4(3):332-42.

[24] Khalilpourazari, S, \& Pasandideh, S H R. Multi-objective optimization of multi-item EOQ model with partial backordering and defective batches and stochastic constraints using MOWCA and MOGWO. Operational Research. 2018; 1-33.

[25] Khalilpourazari, S, \& Pasandideh, S H R. Bi-objective optimization of multi-product EPQ model with backorders, rework process and random defective rate. In Industrial Engineering (ICIE), 2016 12th International Conference on. 2016; (36-40).

[26] Khalilpourazari, S, Pasandideh, S H R, \& Ghodratnama. A. Robust possibilistic programming for multi-item EOQ model with defective supply batches: Whale Optimization and Water Cycle Algorithms. Neural Computing and Applications. 2018; 1-28.

[27] Hwang CL, Masud ASM. Multiple objective decision making, methods and applications: A state-of-the-art survey. Lect Note Econ Math Sys. 1979.

[28] Khalilpourazari, S, \& Khamseh, A A. Bi-objective emergency blood supply chain network design in earthquake considering earthquake magnitude: a comprehensive study with real world application. Annals of Operations Research. 2017; 1-39.

[29] Fazli-Khalaf, M, Khalilpourazari, S, \& Mohammadi, M. Mixed robust possibilistic flexible chance constraint optimization model for emergency blood supply chain network design. Annals of Operations Research. 2017; 1-31.

[30] Pasandideh SHR, Niaki STA, Asadi K. Optimizing a bi-objective multi-product multi-period three echelon supply chain network with warehouse reliability. Exp Sys Appl. 2015; 42:2615-2623.doi: 10.1016/j.eswa.2014.11.018

[31] Khalilpourazari, S, \& Mohammadi, M. Optimization of closed-loop Supply chain network design: a Water Cycle Algorithm approach. In Industrial Engineering (ICIE), 12th International Conference. 2016; (pp. 41-45). IEEE.

[32] Khalilpourazari, S, \& Pasandideh, S H R. Multi-item EOQ model with nonlinear unit holding cost and partial backordering: moth-flame optimization algorithm. Journal of Industrial and Production Engineering. 2017; 34(1), 42-51.

[33] Khalilpourazari, S, \& Khalilpourazary, S. An efficient hybrid algorithm based on Water Cycle and Moth-Flame Optimization algorithms for solving numerical and constrained engineering optimization problems. Soft Computing. 2017; 1-24.

[34] Khalilpourazari, S, Pasandideh, S H R., \& Niaki, S T A. Optimization of multi-product economic production quantity model with partial backordering and physical constraints: SQP, SFS, SA, and WCA. Applied Soft Computing, 49. 2016; 770-791.

[35] Pasandideh, S H R, \& Khalilpourazari, S. Sine Cosine Crow Search Algorithm: A powerful hybrid meta heuristic for global optimization. 2018; arXiv preprint arXiv:1801.08485.

[36] Mohammadi, M, \& Khalilpourazari, S. Minimizing makespan in a single machine scheduling problem with deteriorating jobs and learning effects. In Proceedings of the 6th International Conference on Software and Computer Applications. 2017; (310-315). ACM.

[37] Hwang CL, Yoon K. Methods for Multiple Attribute Decision Making. In: Multiple Attribute Decision Making. Lecture Notes in Economics and Mathematical Systems. 1981; (vol 186). Springer, Berlin, Heidelberg. https://doi.org/10.1007/978-3-642-483. 